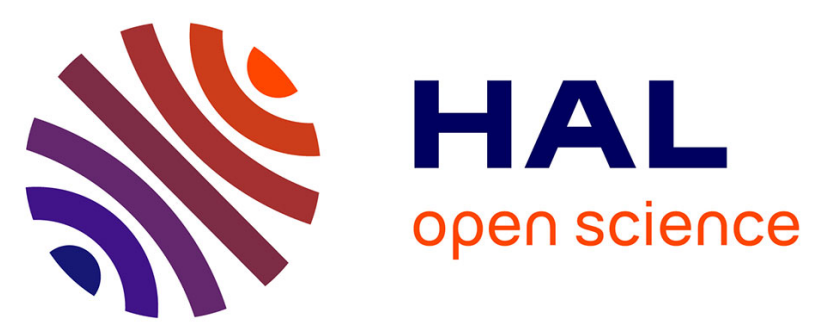

\title{
Stereoselective Syntheses, Structures and Properties of Extremely Distorted Chiral Nanographenes Embedding Hextuple Helicenes
}

\author{
Myriam Roy, Veronika Berezhnaia, Marco Villa, Nicolas Vanthuyne, Michel
}

Giorgi, Jean- Valère Naubron, Salomé Poyer, Valérie Monnier, Laurence

Charles, Yannick Carissan, et al.

\section{To cite this version:}

Myriam Roy, Veronika Berezhnaia, Marco Villa, Nicolas Vanthuyne, Michel Giorgi, et al.. Stereoselective Syntheses, Structures and Properties of Extremely Distorted Chiral Nanographenes Embedding Hextuple Helicenes. Angewandte Chemie International Edition, 2020, 59 (8), pp.3264-3271. 10.1002/anie.201913200 . hal-03064338

\section{HAL Id: hal-03064338 \\ https://hal.science/hal-03064338}

Submitted on 14 Dec 2020

HAL is a multi-disciplinary open access archive for the deposit and dissemination of scientific research documents, whether they are published or not. The documents may come from teaching and research institutions in France or abroad, or from public or private research centers.
L'archive ouverte pluridisciplinaire HAL, est destinée au dépôt et à la diffusion de documents scientifiques de niveau recherche, publiés ou non, émanant des établissements d'enseignement et de recherche français ou étrangers, des laboratoires publics ou privés. 


\title{
Stereoselective Syntheses, Structures and Properties of Extremely Distorted Chiral Nanographenes Embedding Hextuple Helicenes
}

\author{
Myriam Roy, ${ }^{[a, c]}$ Veronika Berezhnaia, ${ }^{[a]}$ Marco Villa, ${ }^{[a]}$ Nicolas Vanthuyne, ${ }^{[b]}$ Michel Giorgi, ${ }^{[d]}$ Jean- \\ Valère Naubron, ${ }^{[\mathrm{d}]}$ Salomé Poyer, ${ }^{[\mathrm{e}]}$ Valérie Monnier, ${ }^{[\mathrm{d}]}$ Laurence Charles, ${ }^{[\mathrm{e}]}$ Yannick Carissan, ${ }^{[\mathrm{b}]}$ Denis \\ Hagebaum-Reignier, ${ }^{[b]}$ Jean Rodriguez, ${ }^{[b]}$ Marc Gingras, ${ }^{*[a]}$ Yoann Coquere ${ }^{*[b]}$
}

\begin{abstract}
We report a molecular design and concept using $\pi$-system elongation and steric effects from helicenes surrounding a triphenylene core toward stable chiral polycyclic aromatic hydrocarbons (PAHs) with a maximal $\pi$-distortion to tackle their aromaticity, supramolecular and molecular properties. The selective syntheses, and the structural, conformational and chiroptical properties of two diastereomeric large multi-helicenes of formula $\mathrm{C}_{90} \mathrm{H}_{48}$ having a triphenylene core and embedding three [5]helicene units on their inner edges and three [7]helicene units at their periphery are reported based on diastereoselective and, when applicable, enantiospecific (!) Yamamoto-type cyclotrimerizations of racemic or enantiopure 9,10-dibromo[7]helicene. Both molecules have an extremely distorted triphenylene core, and one of them exhibits the largest torsion angle recorded so far for a benzene ring (twist $=36.9^{\circ}$ ). The analysis of aromaticity distribution in these model molecules using magnetic criteria revealed a non-aromatic character of their triphenylene cores and provides a new look at aromaticity in threedimensional PAHs. One diastereomer can complex up to three silver(I) ions in the bay region (cavities) of its peripheral [7] helicene units, opening the door to chiral cationic metal-nanographene hybrids.
\end{abstract}

\section{Introduction}

Two-dimensional polycyclic aromatic hydrocarbons (PAHs) are diverse in sizes and shapes, starting from small naphthalene or triphenylene units to graphene sheets and/or flakes having both dimensions larger than $100 \mathrm{~nm}$. Large PAHs can exhibit exceptional electronic and physical properties governed by their

[a] Dr. M. Roy, Dr. M. Villa, Dr. V. Berezhnaia, Prof. Dr. M. Gingras Aix Marseille Univ, CNRS, CINAM, Marseille, France

E-mail: marc.gingras@univ-amu.fr

[b] Dr. N. Vanthuyne, Dr. Y. Carissan, Dr. D. Hagebaum-Reignier, Prof. Dr. J. Rodriguez, Dr. Y. Coquerel

Aix Marseille Univ, CNRS, Centrale Marseille, iSm2, Marseille, France

E-mail: yoann.coquerel@univ-amu.fr

[c] Dr. M. Roy

Sorbonne Université, CNRS, Institut Parisien de Chimie Moléculaire IPCM, F-75005, Paris, France

[d] Dr. M. Giorgi, Dr. J.-V. Naubron, Dr. V. Monnier

Aix Marseille Univ, CNRS, Centrale Marseille, FSCM, Marseille,

France

[e] Dr. S. Poyer, Prof. Dr. L. Charles

Aix Marseille Univ, CNRS, ICR, Marseille, France

Supporting information for this article is given via a link at the end of the document. size and the nature of their periphery. Thus, considerable efforts are currently underway to synthesize well-defined large 2D PAHs such as graphene nanoribbons and nanographenes by organic synthesis (bottom-up approach) in solution or on a surface and to investigate their properties and applications..$^{[1]}$ Because PAHs are somewhat flexible and stretchable molecules, it allows the design of curved PAHs such as bowls, saddles, coiled ribbons, propellers and circular belts with defined molecular chirality. ${ }^{[2]}$ The latter property is of a great interest in life, chemical, and physical sciences as well as technology, because it allows an additional tuning of molecular properties and functions for many applications. ${ }^{[3]}$ Large chiral PAHs have thus become molecules of utmost interest as three-dimensional chiral nanographenes, and small curved PAHs are now often sought as building blocks for their construction in the racemic series. ${ }^{[4]}$ In that direction, multihelicenes have emerged as a class of promising well-defined large chiral $\mathrm{PAHs}^{[5]}$ Multi-helicenes can exist as several diastereomers, each existing as a pair of enantiomers (except in the cases of some achiral meso diastereomers), that can more or less rapidly interconvert depending on the torsional energy and flexibility of the molecules. The proper accumulation of helical strain in multi-helicenes can produce exceptionally distorted molecules showing some benzene units suffering from an extreme torsion angle. For instance, record torsions of $35.3^{\circ}$ and $35.7^{\circ}$ were recently measured in a $D_{2}$-symmetric quadruple helicene ${ }^{[6]}$ and a $C_{2}$-symmetric hextuple helicene, ${ }^{[7]}$ respectively. A fruitful approach to racemic triple helicenes and higher order congeners was based on cyclotrimerization reactions to forge a distorted triphenylene core..$^{[7,8]}$ Using this approach, we report herein the diastereoselective and, when applicable, enantiospecific syntheses of two large and extremely distorted diastereomeric hextuple helicenes of formula $\mathrm{C}_{90} \mathrm{H}_{48}$. The conformational behavior, the structure, the chiroptical properties and the torsion-induced deficient local aromaticity in these molecules are discussed in detail, together with the exploration of the complexation ability toward silver(I) ions for one of them.

\section{Results and Discussion}

Syntheses and conformational properties. It was envisioned that the chiral three-blade propeller-shaped hextuple helicene $D_{3}$ 2 of formula $\mathrm{C}_{90} \mathrm{H}_{48}$ could be prepared by a Yamamoto-type cyclotrimerization of 9,10-dibromo[7]helicene 1 (Figure 1a). This 
(a)<smiles>Brc1c(Br)c2ccc3ccc4cccc5cccc1c5c4c32</smiles>

$\mathrm{Ni}(\operatorname{cod})_{2}, 2,2$ '-bipyridine cis-1,5-cyclooctadiene THF, $130^{\circ} \mathrm{C}, 30 \mathrm{~min}$ $38-39 \%$

(M)-1, >99\% ee

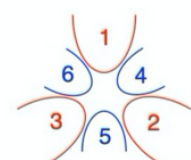

nomenclature $(1,2,3,4,5,6)$
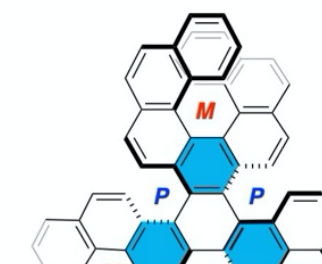

symmetry $D_{3}$ diastereoselective \& enantiospecific synthesis

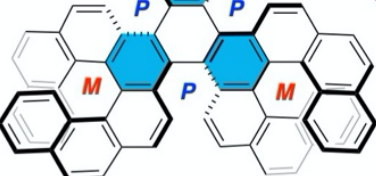

$(-)-(M, M, M, P, P, P)-D_{3}-2,>99 \%$ ee out of 10 possible diastereomers $3 \times(M)-[7]$ helicenes $+3 \times(P)-[5]$ helicenes outer crown inner crown

(c)

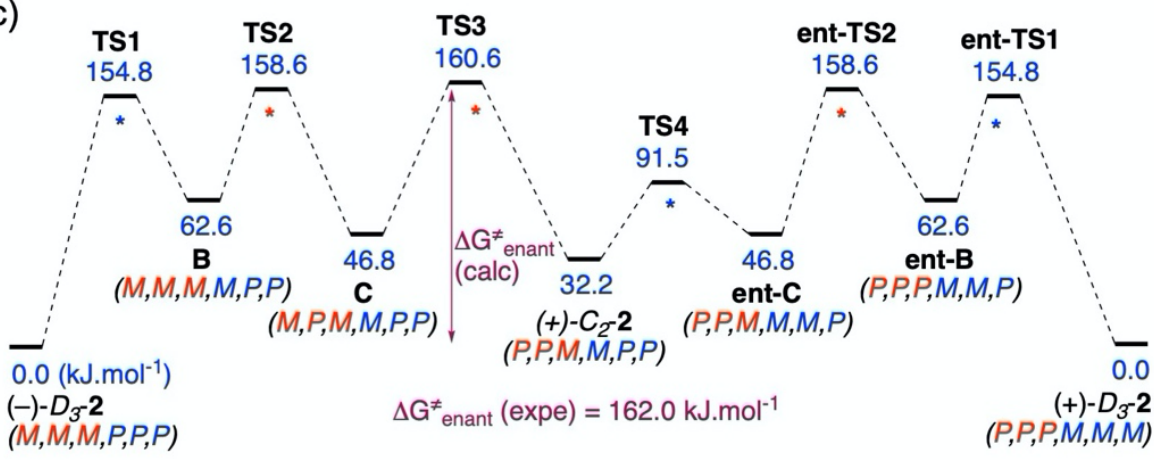

(d)<smiles>Brc1c(Br)c2ccc3ccc4cccc5cccc1c4c3c52</smiles>

$+$<smiles></smiles>

rac-1
$\mathrm{Ni}(\mathrm{cod})_{2}, 2,2$ '-bipyridine cis-1,5-cyclooctadiene THF, $130^{\circ} \mathrm{C}, 30 \mathrm{~min}$

$16 \%$

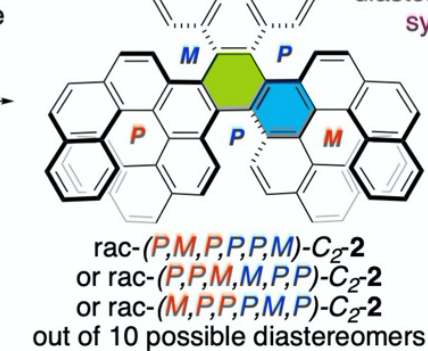

(b)

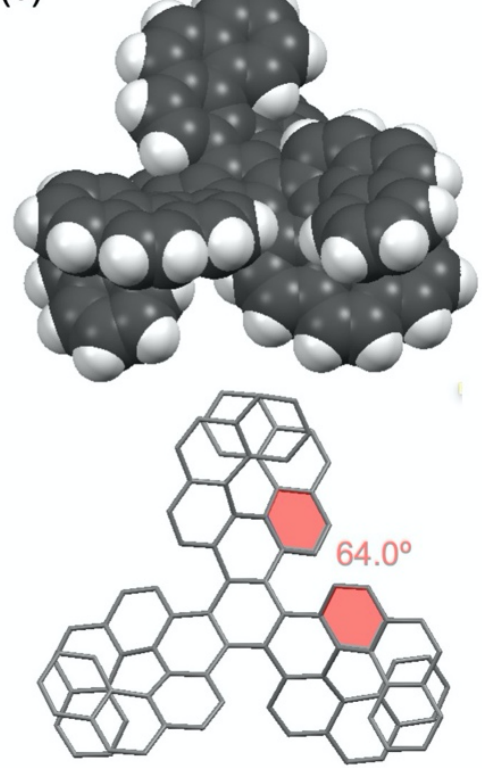

(e)

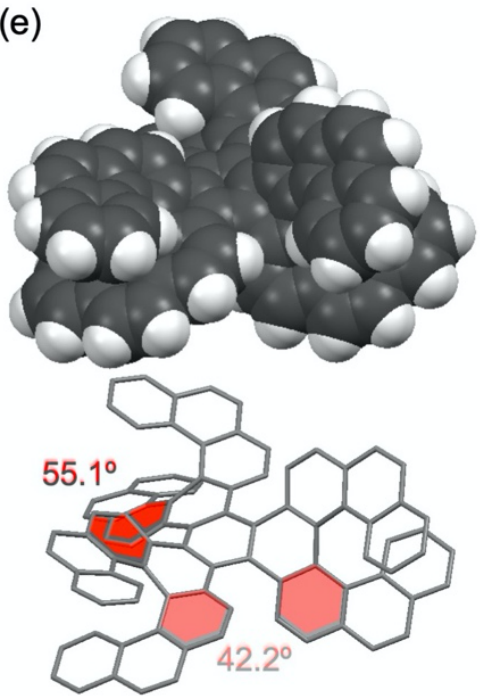

symmetry $C_{2}$ diastereoselective synthesis

Figure 1. Syntheses and some properties of the hextuple helicenes (-)- $D_{3}-2$ and rac- $C_{2}-2$. (a) Yamamoto-type cyclotrimerization of $(M)-9,10-$ dibromo[7]helicene $\left[(M)\right.$-1] leading to $(-)-D_{3}-2$. (b) Three-dimensional representations of $(-)-D_{3}-2$ obtained from single-crystal X-ray diffraction analysis; remarkable interplanar angles are highlighted in red. (c) Simplified plausible enantiomerization pathway of $D_{3}-2$ obtained by DFT calculations [B3LYP/6-31G(d) in the gas phase], energies are

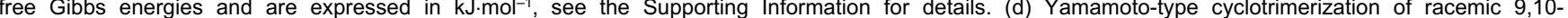
dibromo[7] helicene (rac-1) leading to rac- $C_{2}-2$. (e) Three-dimensional representations of rac- $C_{2}-2$ obtained from single-crystal X-ray diffraction analysis; remarkable interplanar angles are highlighted in red.

new chiral PAH embeds three homochiral [7]helicene units on its outer shell and three homochiral [5]helicene units of opposite configuration on its inner edges. [7]Helicene itself has a high barrier to enantiomerization $\left(178.8 \mathrm{~kJ} \cdot \mathrm{mol}^{-1}\right)^{[9]}$ precluding its inversion of configuration at a significant rate under the projected reaction conditions (ca. $130^{\circ} \mathrm{C}$ ). It was assumed that the barriers to inversion of configuration of the various [7]helicene-containing species involved in the planned nickel(0)-mediated cyclotrimerization would be too high for the synthesis to rely on a thermodynamic control as in previous studies. ${ }^{[7,8]}$ Thus, it should be possible to perform the synthesis from enantiopure $(P)$ - or $(M)$ 1 to obtain the corresponding enantiopure hextuple helicene $D_{3}-2$ in an enantiospecific manner. Indeed, the nickel(0)-mediated cyclotrimerization of $(M)-1$ afforded (-)-(M,M,M,P,P,P)- $D_{3}-2$ in a $38 \%$ yield (Figure 1a). The same reaction performed with $(P)-1$ gave (+)-(P,P,P,M,M,M)- $D_{3}-\mathbf{2}$ in a $39 \%$ yield (not depicted). Both enantiomers of $D_{3}-2$ were thus directly obtained as enantiopure hextuple helicenes, as confirmed by analytical chromatography on a chiral stationary phase. The structure and absolute configuration of (-)-(M,M,M,P,P,P)-D3-2 were unambiguously 
confirmed by single-crystal X-ray diffraction methods (Figure $1 \mathrm{~b}$ ) and circular dichroism spectroscopies (see Supporting Information). On a stereochemical point of view, ten diastereomers of 2 are possible: two of $C_{1}$ symmetry, six of $C_{2}$ symmetry and two of $D_{3}$ symmetry. Their relative free Gibbs energies were calculated by DFT methods from $0.0 \mathrm{~kJ} \cdot \mathrm{mol}^{-1}$ for $D_{3}-2$, the thermodynamic diastereomer, up to $108.3 \mathrm{~kJ} \cdot \mathrm{mol}^{-1}$ for a $\mathrm{C}_{2}$-symmetric metastable diastereomer. A plausible enantiomerization pathway for $D_{3}-2$ was computed with a barrier to enantiomerization calculated at $160.6 \mathrm{~kJ} \cdot \mathrm{mol}^{-1}$ (Figure 1c), in agreement with a value experimentally determined at 162.0 $\mathrm{kJ} \cdot \mathrm{mol}^{-1}$ corresponding to a racemization half-life $\mathrm{t}_{1 / 2}=43$ million years at $25^{\circ} \mathrm{C}$ or 1.3 years at $130{ }^{\circ} \mathrm{C}$. Notably, the barrier to enantiomerization of $D_{3}-\mathbf{2}$ is lower than for the parent [7]helicene, an oddity for $D_{n}$ symmetric multi-helicenes in general. ${ }^{[5]}$ Amusingly, hextuple helicene $D_{3}-2$ is the second triskelion-shaped nanographene reported within a short period of time. ${ }^{[4 \mathrm{e}]}$ The enantiospecific synthesis of both enantiomers of $D_{3}-2$ from either $(P)$ - and (M)-1 confirmed our hypothesis that no significant inversion of configuration of [7] helicene units can occur at a significant rate in the various synthetic intermediates involved in its synthesis. This translated in a unique opportunity to synthesize diastereoselectively a diastereomer of $D_{3}-2$ from racemic 1 , this time mixing helicities of the [7] helicene units at the outer shell of the molecule. Accordingly, the nickel(0)-mediated cyclotrimerization of rac-1 allowed the formation of both the racemic $(P, M, P, P, P, M)-C_{2}-2$ and $D_{3}-2$ diastereomers in a $13.8: 1$ ratio and the isolation of $(P, M, P, P, P, M)-C_{2}-2$ in a $16 \%$ yield (Figure $1 \mathrm{~d})$; note that hextuple helicene rac- $(P, M, P, P, P, M)-C_{2}-2$ can also be denominated rac- $(P, P, M, M, P, P)-C_{2}-2$ or rac$(M, P, P, P, M, P)-C_{2}-2$ according to the proposed nomenclature. The structure and relative configurations of rac- $C_{2}-2$ were ascertained by single-crystal $X$-ray diffraction analysis (Figure 1e). The free Gibbs energy of diastereomer $C_{2}-2$ was calculated at $+32.2 \mathrm{~kJ} \cdot \mathrm{mol}^{-1}$ relative to $D_{3}-2$, and diastereomer $C_{2}-2$ is an intermediate in the computed enantiomerization pathway for $D_{3}-2$ (Figure 1c). The enantiomers of diastereomer $C_{2}-\mathbf{2}$ were separated by chiral HPLC techniques and were fully characterized by chiroptical methods, including the attribution of their absolute configurations (see the Supporting Information).

Structural and chiroptical studies. The structural features of hextuple helicenes $D_{3}-2$ and $C_{2}-2$ were carefully examined (Figure 2). The four benzene units from the triphenylene core of $D_{3}-2$ show a marked alternation of bond lengths from $1.404 \AA$ to $1.465 \AA$ (mean values because of the crystallographic $C_{2-}$ symmetry of $D_{3}-2$ ), to be compared to $1.393 \AA$ in benzene, 1.420 $\AA$ in graphene, and $1.338 \AA$ and $1.454 \AA$ in 1,3 -butadiene, ${ }^{[10 a, b]}$ and may be regarded as their Kekulé structures, i.e. 1,3,5cyclohexatrienes. The central ring in $D_{3}-2$ exists in a chair conformation and the three surrounding rings adopt severely twisted conformations with a mean torsion angle of $32.4^{\circ}$ (Figure 2a). Evaluation of the photophysical properties of $D_{3}-2$ indicated a maximal absorption at $417 \mathrm{~nm}\left(\varepsilon=90000 \mathrm{M}^{-1} \mathrm{~cm}^{-1}\right)$ and maximal emission at $538 \mathrm{~nm}$ (quantum yield $=5.7 \%$ ). The optical rotation of $(M, M, M, P, P, P)-D_{3}-2$ was measured at $[\alpha]_{D}{ }^{25}=-300(\mathrm{c}=0.0325$, $\mathrm{CHCl}_{3}$ ), which is an unexpectedly small absolute value when compared to the large optical rotation values of isolated $(P)$ $[5]$ helicene $\left([\alpha]_{D}{ }^{25}=+1670\right)$ and $(M)$-[7]helicene $\left([\alpha]_{D}{ }^{25}=-5900\right)$. Similarly, the electronic and vibrational circular dichroism spectra of $D_{3}-2$ were found of low intensity (see the Supporting Information). It was reasoned that the strong contribution to the chiroptical properties of the three moderately stretched homochiral (M)-[7]helicene units at the outer shell in $(M, M, M, P, P, P)-D_{3}-2$ (mean interplanar angle of the two terminal rings $=39.7^{\circ}$ vs $32.3^{\circ}$ in $[7]$ helicene itself $\left.{ }^{[11 a, b]}\right)$ is somehow compensated by a strong contribution of opposite intensity of the three severely stretched homochiral $(P)$-[5]helicene units at its edges (mean interplanar angle of the two terminal rings $=64.0^{\circ}$

(a)

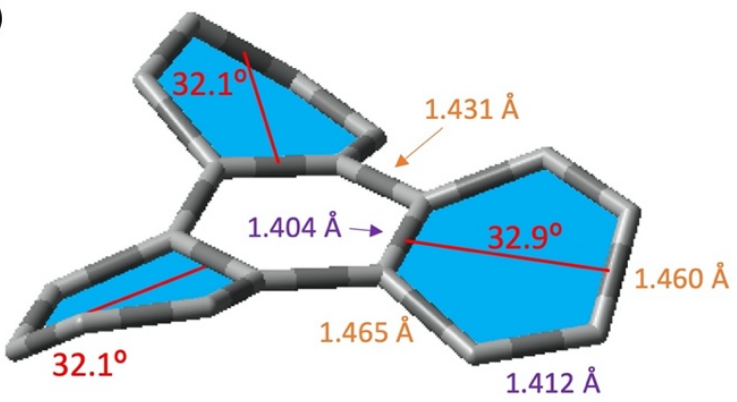

(b)

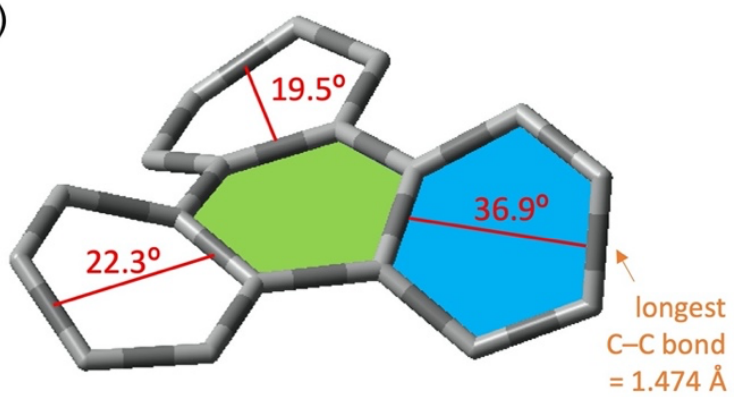

(c)

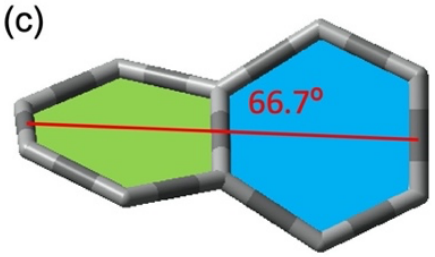

(d)

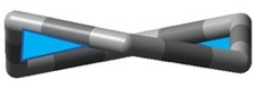

Figure 2. Some structural features of $D_{3}-2$ and $C_{2}-2$. (a) The triphenylene core in $D_{3}-2$ including remarkable torsion angles and bond lengths (mean values). The solid-state conformation of $D_{3}-2$ has crystallographic $C_{2}$-symmetry, justifying for the non-equivalent torsions in all the three blue-colored rings. (b) The triphenylene core in $C_{2}-2$ including remarkable torsion angles and bond length. The solid-state conformation of $C_{2}-2$ has no crystallographic symmetry, justifying for the non-equivalent torsions in the two white-colored rings. (c) The naphthalene unit along the molecular $C_{2}$ axis in $C_{2}-2$ showing a very high endto-end torsion. (d) Profile view of the most twisted benzene ring in $C_{2}-2$.

vs $46.0^{\circ}$ in [5]helicene itself $\left.{ }^{[11 \mathrm{c}]}\right)$. The structural analysis of $C_{2}-2$ also revealed a pronounced bond lengths alternation of the four benzene units from its triphenylene core, with bond lengths 
generally comparable with those in $D_{3}-\mathbf{2}$. However, the longest interatomic distance in $\mathrm{C}_{2}-2$ is the $\mathrm{C}-\mathrm{C}$ bond crossed by the $\mathrm{C}_{2}$ axis in the periphery of the triphenylene core has a length of 1.474 $\AA$ (Figure $2 b$ ), comparable with the one of the $\mathrm{C}\left(\mathrm{sp}^{2}\right)-\mathrm{C}\left(\mathrm{sp}^{2}\right)$ single bond in some biphenyls. ${ }^{[10 c]}$ The $C_{2}-2$ diastereomer was found significantly more distorted than isomer $D_{3}-2$, with a maximal torsion angle culminating at $36.9^{\circ}$ (!) for the peripheral ring of the triphenylene core on the $C_{2}$ axis, establishing the current record of torsion for a "benzene" ring (Figures 2b,d). Also, the naphthalene unit aligned with the $C_{2}$ axis in $C_{2}-2$ exhibits a very high end-to-end torsion of $66.7^{\circ}$ (Figure $2 \mathrm{c}$, current record = $\left.69.5^{\circ[6]}\right)$. The optical rotation of $(P, M, P, P, P, M)-C_{2}-2$ was measured at $[\alpha]_{\mathrm{D}}{ }^{25}=+705\left(\mathrm{c}=0.0337, \mathrm{CH}_{2} \mathrm{Cl}_{2}\right)$ and its electronic circular dichroism spectrum showed a relatively low intensity (see Supporting Information), chiroptical features comparable with those of diastereomer $D_{3}-2$. The highly distorted structures of $D_{3}$ 2 and $C_{2}-2$ limit the formation of intermolecular $\pi-\pi$ interactions, thus allowing enhanced solubility in organic solvents. This is well illustrated by the crystal packing of $(M, M, M, P, P, P)-D_{3}-2$ that shows few interactions between the individual molecules that stack to form supra-helices of $(P)$ configuration within the crystal, creating large chiral $\mathrm{CDCl}_{3}$ solvent channels organized along the $a$ and $b$ crystallographic axes (Figure 3 ). (a)

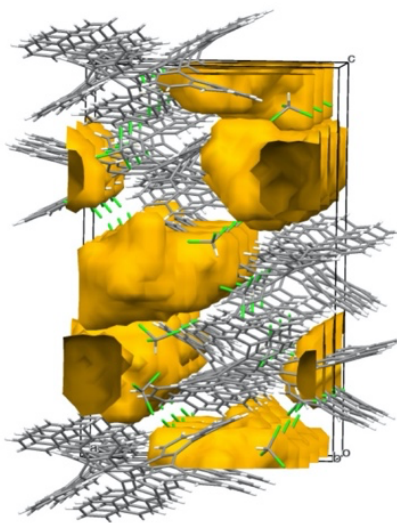

(b)

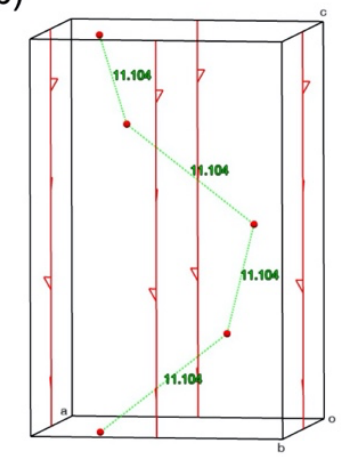

Figure 3. (a) Crystal packing of $(M, M, M, P, P, P)-D_{3}-2$ and representation of the solvent channels along the $b$ axis. The content of the channels is a mix of explicitly determined $d 1$-chloroform molecules and the calculated mask of solvent (yellow voids). (b) Representation of the $(P)$-configured supra-helix (pitch $=$ crystallographic $\mathrm{c}$ vector $=27.2785 \AA$ ) in the crystal packing of $(M, M, M, P, P, P)-D_{3}-2$ : side view along the $c$ axis, the four-fold $4_{3}$ screw axis is in red, the centroids of the central rings of each molecule are represented as red dots and the distances between them $(\AA)$ are noted in green.

Evaluation of aromaticity. The hextuple helicenes $D_{3-2}$ and $C_{2-}$ 2 sustain unprecedented distortion for stable PAHs, pointing out for unusual deficiencies in local aromaticity. Aromaticity is an extremely useful and popular concept in chemistry although there is no single quantitative definition of it, and it is not directly measurable experimentally. ${ }^{[12]}$ Application of the qualitative Clar's rule ${ }^{[13]}$ to $D_{3}-2$ (or $C_{2}-\mathbf{2}$, stereochemistry is not accounted for in Clar's structures) predicts an alternation of local aromaticity with 13 separated $\pi$-sextets in the Clar's structure containing the largest number of disjoint aromatic $\pi$-sextets (Figure $4 d$ ), and nine disjoint $\pi$-sextets in the complementary Clar's structure. However, the Clar's rule is strictly valid for planar polycyclic aromatic systems. Structural-[14] energetic-[15] electron density-based, ${ }^{[16]}$ and magnetic-based indices ${ }^{[17]}$ have been developed to characterize and to quantify aromaticity as a property of molecules. However, these indices were also developed for planar systems and their transposition to three-dimensional systems can lead to erratic results. For instance, it was earlier recognized that the popular structural-based indices as HOMA (Harmonic Oscillator Model of Aromaticity) and energetic-based indices as TRE (Topological Resonance Energy), as well as some electron density-based methods, do not perform well for coiled systems as [n] helicenes and can lead to discrepancies. ${ }^{[18]}$ Indeed, we experienced difficulties with the HOMA during our early work (see Supporting Information). Actually, only magnetic-based methods appear applicable to severely twisted aromatics. When an external magnetic field is applied to a molecule, strong induced electrons currents are created at aromatic (diatropic currents) and antiaromatic (paratropic currents) rings. The ACID (Anisotropy of the Induced Current Density) method ${ }^{[19]}$ allows the visualization of an isosurface on which the induced current density vectors are plotted, showing diatropic (clockwise, aromatic) and paratropic (counterclockwise, antiaromatic) currents. However, the method is sensitive to the orientation of the applied external magnetic field, normally perpendicular to the molecular plane, which can be problematic with highly distorted PAHs such as $D_{3}-\mathbf{2}$ and $C_{2}-\mathbf{2}$. The NICS (Nucleus Independent Chemical Shifts) index relies on the computation of the local magnetic environment at any desired point in space, often referred to as a ghost atom, and is expressed in ppm. ${ }^{[20]} \mathrm{NICS}(0)$ values refer to ghost atoms placed at the center of each cycle, with large negative NICS $(0)$ probing induced diatropic ring currents attributed to aromaticity. For instance, benzene has a $\operatorname{NICS}(0)$ calculated at $-8.6 \mathrm{ppm}$ at the level of theory employed herein. Although the combination of both methods allows for a qualitative and quantitative description of the induced electron currents, it should be kept in mind that the connection between induced diatropic ring currents and aromaticity is not straightforward. ${ }^{[12 b, 17]}$

The NICS analysis of $D_{3}-2$ (Figure 4a) allowed identifying three groups of rings with distinct local aromaticity: i) the A and $B$ rings of the triphenylene core have $\operatorname{NICS}(0)$ values comprised between -0.6 and $+0.8 \mathrm{ppm}$ accounting for poorly directional induced ring currents indicating a non-aromatic character of these two rings; ii) the $C$ and $D$ rings have deficient induced diatropic ring currents with $\mathrm{NICS}(0)$ values calculated around $-5.3 \mathrm{ppm}$ pointing out for marked deficient local aromaticity; and iii) the terminal $\mathrm{E}$ rings with $\mathrm{NICS}(0)$ values of $-9.6 \mathrm{ppm}$ denoting full aromaticity. The over-estimation of NICS in the terminal rings of [7] helicene is documented and is due to the magnetic coupling with the neighboring ring placed below or above. ${ }^{[17 a]}$ Notably, for each [5]helicene and [7]helicene subunit in $D_{3}-2$ an overall lower aromaticity than for the parent isolated [5] helicene and [7] helicene was computed (see graphs in Figure 4a). Also, the distribution of local aromaticity in the [7] helicene units in $D_{3}-2$ differs significantly from the one of isolated [7] helicene with the central ring $B$ being non-aromatic in $D_{3}-\mathbf{2}$. In order to differentiate torsional effects 
(a)

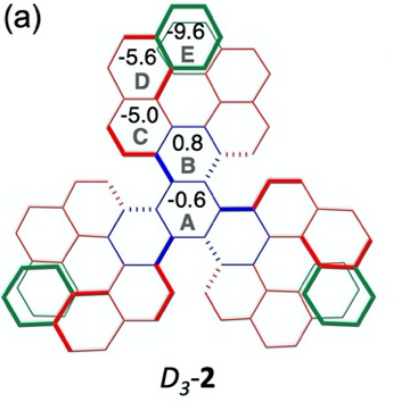

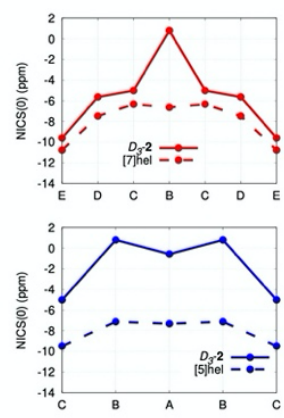

(b)

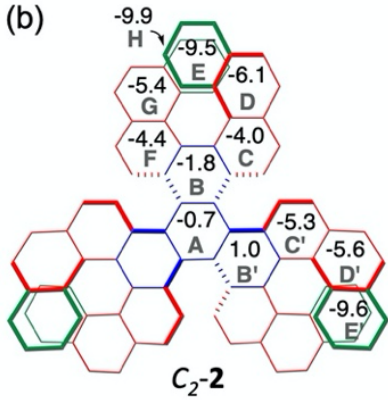

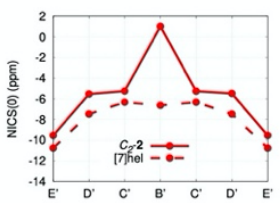
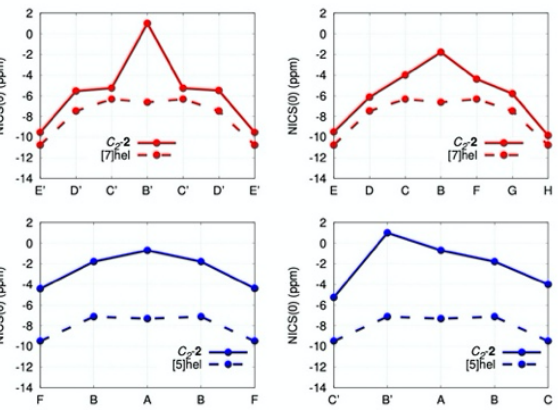

(c)

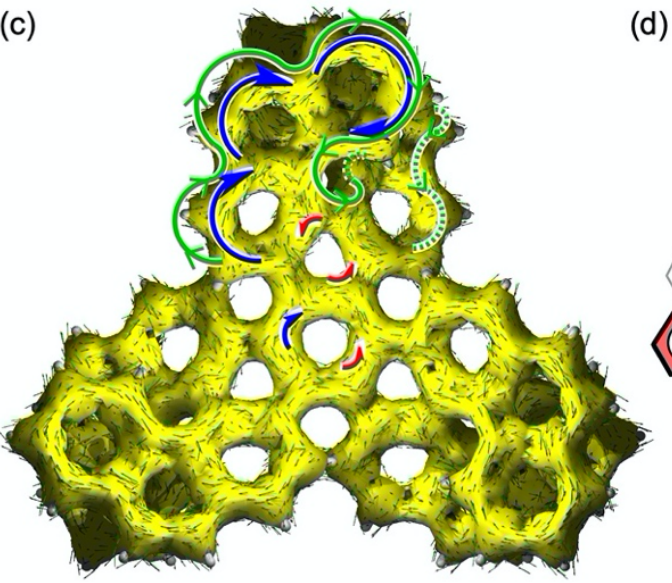

(d)

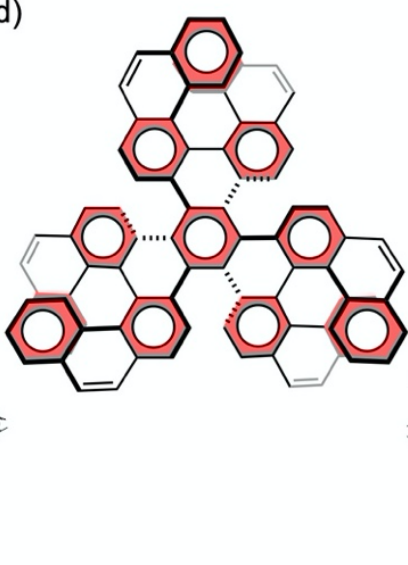

(e)

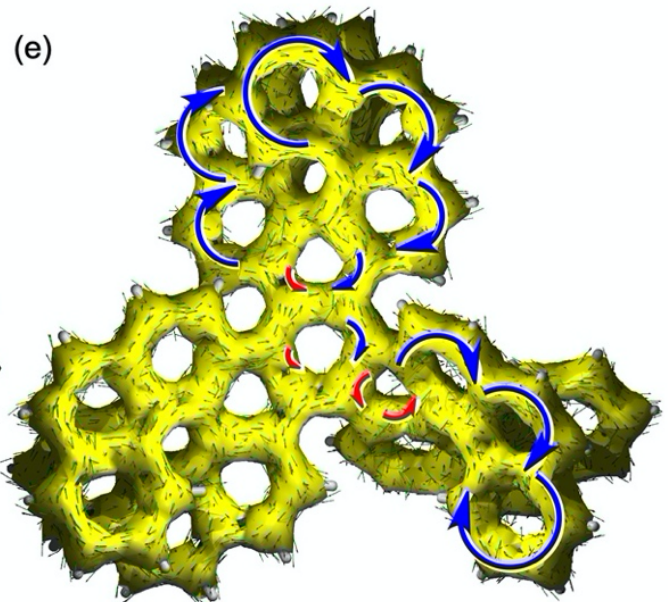

Figure 4. Aromaticity analysis in $D_{3}-2$ and $C_{2}-2$. (a) NICS(0) values for all non-equivalent rings in $D_{3}-2$. The graphs show the NICS(0) values for the [7] helicene and [5]helicene units in $D_{3}-2$ (solid red and blue lines, respectively) and isolated [7]helicene and [5]helicene (dashed lines). (b) NICS(0) values for all non-equivalent rings in $C_{2}$-2. The graphs show the NICS(0) values for the [7]helicene and [5]helicene units in $C_{2}-2$ (solid red and blue lines, respectively) and isolated [7] helicene and [5] helicene (dashed lines). (c) ACID plot of $D_{3}-2$, the magnetic field is applied along the $+z$ axis perpendicular to the view plane pointing to the observer, diatropic currents are highlighted with blue and green arrows and paratropic currents are highlighted with red arrows. (d) Clar's perspective of $D_{3}-2$ showing 13 separated $\pi$ sextets; the Clar's perspective of $C_{2}-2$ would be identical. (e) ACID plot of $C_{2}-2$, the magnetic field is applied along the +z axis perpendicular to the view plane pointing to the observer, diatropic currents are highlighted with blue arrows and paratropic currents are highlighted with red arrows.

from through-space and conjugation effects in the NICS(0) calculations of the triphenylene cores of both $D_{3}-2$ and $C_{2}-2$, the $\mathrm{NICS}(0)$ were also computed for the virtual triphenylene molecules having the distorted geometries $D_{3}-2$ and $C_{2}-2$ (see the Supporting Information). Comparison with the NICS(0) of triphenylene itself showed an augmentation of ca. $+2 \mathrm{ppm}$ for the distorted rings when compared to their planar counterparts, showing that torsional effects have a significant contribution to the unusual NICS $(0)$ value computed for $D_{3}-2$ and $C_{2}-2$. The ACID plot of $D_{3}-2$ (Figure 4c) confirmed the NICS analysis: the external $\mathrm{E}$ rings display clear and strong diatropic ring currents consistent with full aromaticity, the $C$ and $D$ rings exhibit dominant diatropic ring currents but of lower intensity, while the $A$ and $B$ rings show competing small diatropic and paratropic currents indicating weak electronic delocalization and a non-aromatic character. The triphenylene core in $D_{3}-2$ is probably the least aromatic known triphenylene unit, which correlates with its unprecedented torsion. More globally, a strong diatropic macrocyclic ring current is clearly visible at the periphery of the whole molecular architecture showing global electronic delocalization, which is certainly compensating for the severe distortions of the $\pi$-systems and contributing to the thermodynamic stability. The analysis of local aromaticity in diastereomer $C_{2}-\mathbf{2}$ revealed comparable features to the one of $D_{3}-2$ with however a more complex situation due to the lower symmetry of the molecule (Figures $4 \mathrm{~b}, \mathrm{e}$ ). Notably, the two homochiral [7] helicene units (those not crossed by the $C_{2}$ axis) and the triphenylene core have different $\operatorname{NICS}(0)$ values. The ACID plot of $C_{2}-2$ confirmed qualitatively its overall distribution of local aromaticity. Altogether, the multi-helicenes $D_{3}-\mathbf{2}$ and $C_{2}-\mathbf{2}$ are PAHs whose local aromaticity is subjected to variations of large amplitudes from entirely aromatic at the edges to nonaromatic at the cores, correlating the distribution of distortion in the molecules.

Complexation properties of multi-helicene $D_{3}-2$. [7]Helicene itself was earlier demonstrated to behave as a chiral molecular tweezer for silver(I) ions, the metallic cation being sandwiched between the two outermost bonds of the helicene (C3-C4). ${ }^{[21]}$ It was hypothesized that hextuple helicene $D_{3}-2$ embedding three identical and moderately stretched [7]helicene units on its outer shell could behave as a mono, bis or triple tweezer capable of complexing up to three silver(I) ions to form some original chiral cationic metal-nanographene hybrids (Figure 5). The binding energies for the iterative complexation of one, two 
and three silver(I) ions inside the bay region of three [7] helicene units in $D_{3}-2$ were evaluated by DFT calculations and compared to the one of $\mathrm{Ag}^{+}$with [7]helicene ${ }^{[21]}$ (see the Supporting Information). This model study indicated a slightly better

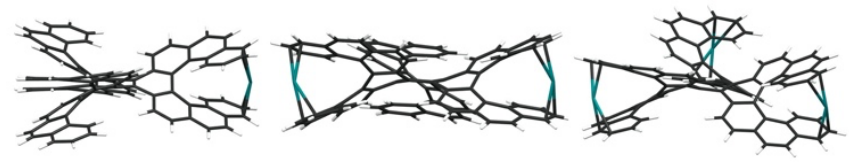

Figure 5. Computationally optimized structures of the most stable mono, bis and triscationic $\mathrm{Ag}^{+}$complexes of $D_{3}-2$ (DFT, wB97XD/Def2TZVP//wB97XD/Def2SVP, gas phase). Left : $\left[\mathrm{Ag} \subset \mathrm{D}_{3}-2\right]^{+}$, middle : $\left[2 \mathrm{Ag} \subset D_{3}-2\right]^{2+}$, right : $\left[3 \mathrm{Ag}^{+} \subset D_{3}-2\right]^{3+}$.

stabilization for $\left[\mathrm{Ag} \subset \mathrm{D}_{3}-2\right]^{+}$than for $[\mathrm{Ag} \subset[7] \text { helicene }]^{+}$, and also that triscation $\left[3 \mathrm{Ag} \subset D_{3}-2\right]^{3+}$ should be reasonably stable. Experimentally, a methanol/dichloromethane solution of $D_{3}-2$ and $\mathrm{AgNO}_{3}$ (1:1) was analyzed by electrospray ionization mass spectrometry (ESI-MS) using very soft conditions, drastically limiting the generation of ions upon collision in the interface of the mass spectrometer (i.e. in the gas phase), so that most, if not all, observables result from the electrospray of cationic species initially present in solution. The formation of both the cation $\left[\mathrm{Ag} \subset \mathrm{D}_{3}-2\right]^{+}$and the biscation $\left[2 \mathrm{Ag} \subset D_{3}-2\right]^{2+}$ in the solution could be clearly evidenced. However, performing ion mobility separation (IMS) prior to mass analysis to further enhance the dynamic range of detection permitted to evidence that $\left[3 \mathrm{Ag} \subset D_{3^{-}}\right.$ $2]^{3+}$ is also a stable complex. The relative stability of the three silver adducts was evaluated by the 11.2:100:3.8 abundance ratio measured for $\left[\mathrm{Ag} \subset D_{3}-2\right]^{+} /\left[2 \mathrm{Ag} \subset D_{3}-2\right]^{2+} /\left[3 \mathrm{Ag} \subset D_{3}-2\right]^{3+}$ by IMS$\mathrm{MS}$, clearly showing the biscationic $\left[2 \mathrm{Ag} \subset D_{3}-2\right]^{2+}$ complex as the most stable one when observed as naked gas phase ions. The actual reasons for this preference remain unclear at this stage and may include the existence of a more compact and better adjusted conformation for biscationic $\left[2 \mathrm{Ag} \subset D_{3}-2\right]^{2+}$ than for its mono- and triscationic analogues as seemingly indicated by the experimental determination of collision cross sections (see Supporting Information).

\section{Conclusions}

The molecular design and concept using $\pi$-system elongation and steric effects, based on helical strains surrounding a triphenylene core with configurationally stable [7]helicenes, has led to extreme distortion in some chiral PAHs. This idea was put into practice through a nickel(0)-mediated cyclotrimerization of enantiopure and racemic 9,10-dibromo[7]helicene, which diastereoselectively afforded large chiral hextuple helicenes of formula $\mathrm{C}_{90} \mathrm{H}_{48}$ with $D_{3}$ and $C_{2}$ symmetry, respectively. The diastereomer with $D_{3}$ symmetry is a three-blade propeller-shaped chiral nanographene that embeds three homochiral [7]helicene units on its outer shell and three homochiral [5] helicene units of opposite configuration on its inner edges. Both $D_{3}$-symmetric enantiomers were directly obtained as enantiopure materials by an enantiospecific Yamamoto-type cyclotrimerization, a premiere for large chiral
PAHs, and a first example for this type of cyclotrimerization. The structural analysis of this molecule revealed a highly distorted triphenylene core with a marked bond lengths alternation of the six-membered rings. The diastereomer with $C_{2}$-symmetry embeds three [7]helicene units of mixed helicity on its outer shell, and three [5] helicene units of mixed helicity on its inner edges so that four $(P)$-configured and two $(M)$-configured helicenes are present in the molecule. Its structural analysis also enlightened a pronounced alternation of bond lengths in its triphenylene core, and more remarkably extreme torsions establishing new limits for benzene (twist $=36.9^{\circ}$ ). The chiroptical properties of the two hextuple helicenes were found of relatively small magnitude, possibly due to a phenomenon of compensation between the intertwined $(P)$ - and $(M)$-configured helicenes. Aromaticity was computationally analyzed in these fascinating molecules using several methods, which was complicated not only because the quantification of the concept of aromaticity is intrinsically difficult, but also because existing models of aromaticity were developed for planar PAHs. Nevertheless, magnetic-based methods known as NICS and ACID proved to be useful, though not ideal, and they revealed a non-aromatic character of the triphenylene cores in both diastereomeric hextuple helicenes, in correlation to the severe distortion of the rings. An early exploration of the metal ions avidity and supramolecular properties of the $D_{3}$-symmetric diastereomer revealed its ability to bind up to three silver(I) ions in the bay regions (cavities) of three [7] helicene units at its outer shell, as evaluated by the combination of DFT simulations with advanced mass spectrometry methods, opening the door to the field of chiral cationic metal-nanographene hybrids. To sum it up, the present study pushes the limits on the design and the synthesis of highly distorted chiral PAHs, where chirality provides additional control on molecules for modulating their properties for applications in chemical and materials science. It also deepens the knowledge on the conformational, chiroptical and supramolecular properties (solid and solution states) of chiral $\mathrm{PAHs}$ and nanographenes, and raises questions about aromaticity in these large distorted molecules.

\section{Experimental Section}

Detailed experimental procedures for the syntheses of (-)- $D_{3}-\mathbf{2},(+)-D_{3}-2$ and rac- $C_{2}-2$, the resolution of rac- $C_{2}-2$ by HPLC methods, the spectroscopic, structural, chiroptical, and photophysical characterization of all compounds, the experimental and computational enantiomerization study of $D_{3}-2$, the full-detail analysis of aromaticity in $D_{3}-2, C_{2}-2$ and related molecules, the full-detail complexation study of silver(I) cations with $D_{3}-\mathbf{2}$, and the crystallographic data for (-)-(M,M,M,P,P,P)- $D_{3}-2$ (CCDC 1835903) and rac- $(P, M, P, P, P, M)-C_{2}-2$ (CCDC 1902495) are included as supporting information for this article.

\section{Acknowledgements}

We thank Mrs. R. Rosas (Aix-Marseille Univ.) and Mrs. C. Troufflard (Sorbonne Univ.) for assistance with NMR spectroscopy, Prof. Dr. P. Ceroni (Univ. of Bologna) for assistance with photophysics, Mrs. M. Jean (CNRS) for assistance with HPLC, and the Centre Régional de Compétences 
en Modélisation Moléculaire (Aix-Marseille Univ.) for computing facilities. Financial support from a CNRS PICS (No.PICS07573) with the University of Bologna, the French-Italian University for a doctoral contract to M.V. (No C2-141 - Vinci program), AMIDEX (Pyrenex, A-M-AAP-EI-17-171-170301-11.50-GINGRAS-SAT), Aix-Marseille Université and the Centre National de la Recherche Scientifique (CNRS) is gratefully acknowledged.

Keywords: helicenes - polycyclic aromatic hydrocarbons • stereoselectivity $\bullet$ strained molecules $\bullet$ aromaticity

[1] a) A. Narita, X.-Y. Wang, X. Feng, K. Müllen, Chem. Soc. Rev. 2015, 44 6616; b) X.-Y. Wang, A. Narita, K. Müllen, Nat. Rev. Chem. 2017, 2, 100.

[2] Reviews: a) M. Rickhaus, M. Mayor, M. Juriček, Chem. Soc. Rev. 2016 45, 1542; b) M. Rickhaus, M. Mayor, M. Juríček, Chem. Soc. Rev. 2017 46, 1643; c) M. A. Majewski, M. Stępień, Angew. Chem. Int. Ed. 2019, 58, 86; d) Y. Segawa, H. Ito, K. Itami, Nat. Rev. Mats 2016, 1, 15002; e) M. Gingras, Chem. Soc. Rev. 2013, 42, 968; f) M. Gingras, G. Felix, R. Peresutti, Chem. Soc. Rev. 2013, 42, 1007; g) M. Gingras, Chem. Soc. Rev. 2013, 42, 1051; h) Y. Shen, C.-F. Chen, Chem. Rev. 2012, 112 1463; i) M. Ball, Y. Zhong, Y. Wu, C. Schenck, F. Ng, M. Steigerwald, S Xiao, C. Nuckolls, Acc. Chem. Res. 2015, 48, 267; j) A. Bedi, O. Gidron, Acc. Chem. Res. 2019, 52, 2482. Selected recent reports: k) K. Y. Cheung, C. K. Chan, Z. Liu, Q. Miao, Angew. Chem. Int. Ed. 2017, 56, 9003; I) M. Daigle, D. Miao, A. Lucotti, M. Tommasini, J.-F. Morin, Angew. Chem. Int. Ed. 2017, 56, 6213; m) C. M. Cruz, S. Castro-Fernández, E. Maçôas, J. M. Cuerva, A. G. Campaña, Angew. Chem. Int. Ed. 2018, 57 , 14782; n) Y. Nakakuki, T. Hirose, H. Sotome, H. Miyasaka, K. Matsuda, J. Am. Chem. Soc. 2018, 140, 4317; o) G. Povie, Y. Segawa, T. Nishihara, Y. Miyauchi, K. Itami, J. Am. Chem. Soc. 2018, 140, 10054 p) G. R. Kiel, S. C. Patel, P. W. Smith, D. S. Levine, T. D. Tilley, J. Am. Chem. Soc. 2017, 139, 18456; q) N. J. Schuster, R. H. Sánchez, D. Bukharina, N. A. Kotov, N. Berova, F. Ng, M. Steigerwald, C. Nuckolls, J. Am. Chem. Soc. 2018, 140, 6235.

[3] J. R. Brandt, F. Salerno, M. J. Fuchter, Nat. Rev. Chem. 2017, 1, 45.

[4] a) J. M. Fernández-García, P. J. Evans, S. M. Rivero, I. Fernández, D. García-Fresnadillo, J. Perles, J. Casado, N. Martín, J. Am. Chem. Soc. 2018, 140, 17188; b) K. Kato, Y. Segawa, L. T. Scott, K. Itami, Angew. Chem. Int. Ed. 2018, 57, 1337; c) P. J. Evans, J. Ouyang, L. Favereau, J. Crassous, I. Fernández, J. Perles, N. Martín, Angew. Chem. Int. Ed. 2018, 57, 6774; d) T. Fujikawa, D. V. Preda, Y. Segawa, K. Itami, L. T. Scott, Org. Lett. 2016, 18, 3992; e) C. M. Cruz, I. R. Márquez, S. CastroFernández, J. M. Cuerva, E. Maçôas, A. G. Campaña, Angew. Chem. Int. Ed. 2019, 58, 8068; f) D. Meng, G. Liu, C. Xiao, Y. Shi, L. Zhang, L. Jiang, K. K. Baldridge, Y. Li, J. S. Siegel, Z. Wang, J. Am. Chem. Soc. 2019, 141, 5402

[5] Reviews: a) C. Li, Y. Yang, Q. Miao, Chem. Asian J. 2018, 13, 884; b) K. Kato, Y. Segawa, K. Itami, Synlett 2019, 30, 370. For other multihelicenes: c) A. Pradhan, P. Dechambenoit, H. Bock, F. Durola, J. Org. Chem. 2013, 78, 2266; d) Y. Chen, T. Marszalek, T. Fritz, M. Baumgarten, M. Wagner, W. Pisula, L. Chen, K. Müllen, Chem. Commun. 2017, 53, 8474; e) Y. Zhu, Z. Xia, Z. Cai, Z. Yuan, N. Jiang, T. Li, Y. Wang, X. Guo, Z. Li, S. Ma, D. Zhong, Y. Li, J. Wang, J. Am. Chem. Soc. 2018, 140, 4222; f) Y. Wang, Z. Yin, Y. Zhu, J. Gu, Y. Li, J. Wang, Angew. Chem. Int. Ed. 2019, 58, 587; g) H.-A. Lin, K. Kato, Y. Segawa, L. T. Scott, K. Itami, Chem. Sci. 2019, 10, 2326; h) K. Kawai, K. Kato, L. Peng, Y. Segawa, L. T. Scott, K. Itami, Org. Lett. 2018, 20, 1932; i) R. Yamano, Y. Shibata, K. Tanaka, Chem. Eur. J. 2018, 24, 6364; j) Y. Zhu, X. Guo, Y. $\mathrm{Li}$, J. Wang J. Am. Chem. Soc. 2019, 141, 5511; k) During the evaluation process of this manuscript, Ravat and coworkers also reported the enantiospecific synthesis of (-)- $D_{3}-2$ from (-)-9,10-dibromo[7]helicene using the nickel-mediated Yamamoto cyclotrimerization that we previously made use of (see ref [8f]): F. Zhang, E. Michail, F. Saal, A.-M. Krause, P. Ravat, Chem. Eur. J. DOI: 10.1002/chem.201904962. For cyclohelicenes, see: I) A. Robert, P. Dechambenoit, E. A. Hillard, H. Bock, F. Durola, Chem. Commun. 2017, 53, 11540; m) G. Naulet, L. Sturm, A. Robert, P. Dechambenoit, F. Röhricht, R. Herges, H. Bock, F. Durola, Chem. Sci. 2018, 9, 8930; n) A. Robert, G. Naulet, H. Bock, N. Vanthuyne, M. Jean, M. Giorgi, Y. Carissan, C. Aroulanda, A. Scalabre, E. Pouget, F. Durola, Y. Coquerel, Chem. Eur. J. 2019, 25, 14364.

[6] T. Fujikawa, Y. Segawa, K. Itami, J. Am. Chem. Soc. 2016, 138, 3587.

[7] T. Hosokawa, Y. Takahashi, T. Matsushima, S. Watanabe, S. Kikkawa, I. Azumaya, A. Tsurusaki, K. Kamikawa, J. Am. Chem. Soc. 2017, 139, 18512.

[8] a) L. Barnett, D. M. Ho, K. K. Baldridge, R. A. Pascal Jr., J. Am. Chem. Soc. 1999, 121, 727; b) D. Peña, D. Pérez, E. Guitían, L. Castedo, Org. Lett. 1999, 1, 1555; c) D. Peña, A. Cobas, D. Pérez, E. Guitían, L. Castedo, Org. Lett. 2000, 2, 1629; d) M. A. Bennett, M. R. Kopp, E. Wenger, A. C. Willis, J. Organomet. Chem. 2003, 667, 8; e) A. Pradhan, P. Dechambenoit, H. Bock, F. Durola, Angew. Chem. Int. Ed. 2011, 50, 12582; f) V. Berezhnaia, M. Roy, N. Vanthuyne, M. Villa, J.-V. Naubron, J. Rodriguez, Y. Coquerel, M. Gingras, J. Am. Chem. Soc. 2017, 139, 18508; g) R. Zuzak, J. Castro-Esteban, P. Brandimarte, M. Engelund, A. Cobas, P. Piątkowski, M. Kolmer, D. Pérez, E. Guitían, M. Szymonski, D. Sánchez-Portal, S. Godlewski, D. Peña, Chem. Commun. 2018, 54, 10256; h) I. Pozo, E. Guitían, D. Pérez, D. Peña, Acc. Chem. Res. 2019, 52, 2472.

[9] R. H. Martin, M. J. Marchant, Tetrahedron 1974, 30, 347.

[10] a) F. H. Allen, O. Kennard, D. G. Watson, L. Brammer, A. G. Orpen, R. Taylor, J. Chem. Soc., Perkin Trans. 2 1987, S1; b) N. C. Craig, P. Groner, D. C. McKean, J. Phys. Chem. A. 2006, 110, 7461; c) G. Casalone, A. Gavezzotti, M. Simonetta, J. Chem. Soc., Perkin Trans. 2 1973, 342.

[11] a) P. T. Beurskens, G. Beurskens, T. E. M. van den Hark, Cryst. Struct. Comm. 1976, 5, 241; b) T. E. M. van den Hark, P. T. Beurskens, Cryst. Struct. Comm. 1976, 5, 247; c) R. Kuroda, J. Chem. Soc. Perkin Trans. 2 1982, 789.

[12] a) For the definition of aromaticity by IUPAC, see: https://goldbook.iupac.org/html/A/A00442.html; b) A. Stanger, Chem. Commun. 2009, 1939; c) J. Grunenberg, Int. J. Quant. Chem. 2017, 117, e25359.

[13] M. Solá, Front. Chem. 2013, 1, 22.

[14] T. M. Krygowski, H. Szatylowicz, O. A. Stasyuk, J. Dominikowska, M. Palusiak, Chem. Rev. 2014, 114, 6383.

[15] a) M. K. Cyrański, Chem. Rev. 2005, 105, 3773; b) J.-i. Aihara, Bull. Chem. Soc. Jpn 2016, 89, 1425.

[16] F. Feixas, E. Matito, J. Poater, M. Solá, Chem. Soc. Rev. 2015, 44, 6434.

[17] R. Gershoni-Poranne, A. Stanger, Chem. Soc. Rev. 2015, 44, 6597.

[18] a) G. Portella, J. Poater, J. M. Bofill, P. Alemany, M. Solá, J. Org. Chem. 2005, 70, 2509; b) H. Kalam, A. Kerim, K. Najmidin, P. Abdurishit, T. Tawar, Chem. Phys. Lett. 2014, 592, 320; c) D. W. Szczepanik, M. Andrzejak, J. Dominikowska, B. Pawetek, T. M. Krygowski, H. Szatylowicz, M. Solá, Phys. Chem. Chem. Phys. 2017, 19, 28970.

[19] a) D. Geuenich, K. Hess, F. Köhler, R. Herges, Chem. Rev. 2005, 105, 3758; b) R. Herges, Magnetic Properties of aromatic compounds and aromatic transition states, in The Chemical Bond: Chemical Bonding Across the Periodic Table, (Frenking, G.; Shaik, S. Eds) Wiley-VCHVerlag, 2014.

[20] Z. Chen, C. S. Wannere, C. Corminboeuf, R. Puchta, P. von R. Schleyer, Chem. Rev. 2005, 105, 3842.

[21] a) M. J. Fuchter, J. Schaefer, D. K. Judge, B. Wardzinski, M. Weimar, I. Krossing, Dalton Trans. 2012, 41, 8238; b) E. Makrlík, B. Klepetářová, D. Sýkora, S. Böhm, P. Vaňura, J. Storch, Chem. Phys. Lett. 2015, 635, 355. 